\title{
SIMPOSIO INTERNACIONAL "LATIN AMERICA AND CENTRAL EUROPE IN 1968: POLITICAL LEFT, SOCIAL MOVEMENTS AND MUTUAL INFLUENCES IN THE YEAR OF UPHEAVALS" (Centro de Estudios Ibero-Americanos de la Universidad Carolina, Praga, 7 y 8 de diciembre de 2018)
}

Los días 7 y 8 de diciembre de 2018 tuvo lugar el simposio internacional con el título "Latin America and Central Europe in 1968: Political Left, Social Movements and Mutual Influences in the Year of Upheavals". Este evento fue organizado por el Centro de Estudios Ibero-Americanos de la Universidad Carolina, con la participación de académicos especializados en la problemática de las relaciones entre Europa Central y América Latina en el siglo XX. El idioma oficial del simposio fue el inglés y en el evento han participado investigadores provenientes no sólo de las instituciones checas, sino también de varios países europeos (Italia, Polonia, Bélgica y Austria).

El simposio fue celebrado dentro del aniversario de los 50 años que han transcurrido desde 1968 - un año lleno de acontecimientos con impacto internacional (la masacre de Tlatelolco, la invasión de Checoslovaquia, los movimientos estudiantiles de 1968). El objetivo del evento sin embargo, no fue solamente la conmemoración de estos sucesos históricos, sino también ofrecer unas nuevas perspectivas dentro de la interpretación de las relaciones internacionales entre América Latina y Europa en los años 1960, con un enfoque en los movimientos sociales y la izquierda política.

El evento fue inaugurado por la profesora Markéta Křížová - vicedecana de la Facultad de Filosofía y Letras de la Universidad Carolina, que dedicó su conferencia a la historia del Centro de Estudios Ibero-Americanos de Praga y su establecimiento en el contexto de las rivalidades intelectuales durante la Guerra Fría. Los doctores Lukáš Perutka y Radek Buben, ambos del Centro de Estudios Ibero-Americanos de la Universidad Carolina, analizaron en sus ponencias la reacción del gobierno de Estados Unidos a la masacre de Tlatelolco y respectivamente, la situación de la izquierda política venezolana y sus problemas históricos y actuales. Maurizio Petrocchi (Universidad de Macerata) dedicó su conferencia a las tácticas y estrategias de las guerrillas y la influencia de los revolucionarios latinoamericanos en Europa. Kim Christiaens y Jos Claeys de la Universidad Católica de Lovaina ofrecieron una perspectiva interesante dentro del estudio de la historia de la solidaridad con el Tercer Mundo en los años 1960 y 1970. El historiador austríaco Bernd Hausberger (El Colegio de México) dedicó su ponencia a la cinematografía de los años 1960 y el papel de la Revolución Mexicana. La última conferencia del simposio fue: "El año 1968 como el inicio del cambio político en México" fue presentada por Karol Derwich de la Universidad Jaguelónica.

El debate de la mesa redonda fue celebrado el día 8 de diciembre y dio lugar a una fructífera discusión con unos aportes muy interesantes dentro de la problemática de las relaciones entre América Latina y Europa Central. El simposio fue concluido con una visita guiada por la ciudad de Praga y sus sitios de memoria relacionados con el año revolucionario 1968 .

por Maroš Timko (Praga) (Escrito en español por el autor) 